
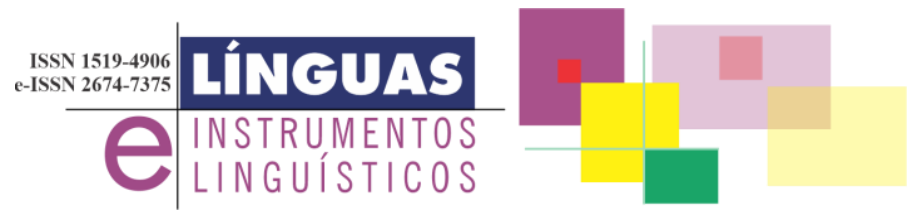

DOI: $10.20396 /$ lil.v23i46.8659235

\title{
AS CONSTRUÇÕES IDENTITÁRIAS EM NARRATIVAS SOBRE MIGRAÇÃO NO SUL DO MARANHÃO
}

\section{IDENTITY CONSTRUCTIONS IN NARRATIVES OF MIGRATION IN SOUTHERN MARANHÃO}

\author{
Marta Piovesan* \\ UEMA \\ Caio Mira** \\ UNISINOS
}

Resumo: Partindo da proposição de que narrativas e identidades emergem de contextos sociais e de que a discursividade é uma lente privilegiada para investigar as práticas sociais e experiências pessoais, a presente pesquisa de caráter interpretativo/qualitativo tem como domínio empírico as narrativas de pessoas que vivenciaram um processo de migração recente em Balsas, cidade do Sul do Maranhão. Nesse cenário, o objetivo principal desta pesquisa é analisar como as identidades, especificamente sob o ponto de vista de quem nasceu na região, são construídas linguística e textualmente em um espaço geográfico marcado pelas transformações sociais e econômicas do movimento migratório recente. As análises das narrativas permitiram evidenciar as identidades em um ambiente de transformações rápidas, com uma multiplicidade de indivíduos, onde as construções identitárias não são unificadas, mas estão sempre em transformação.

Palavras-chave: Narrativas; Identidades; Discurso; Processo migratório.

Abstract: Based on the proposition that narratives and identities emerge from social contexts and that discourse is a privileged lens for investigating social practices and personal experiences, the present research of an interpretative Iqualitative nature has as an empirical domain the narratives of people who experienced a process of recent migration in Balsas, a city in the south of 
Maranhão. In this scenario, the main objective of this research is to analyze how identities, specifically from the point of view of those who were born in the region, are constructed linguistically and verbatim in a geographical space marked by the social and economic transformations of the migratory movement. The analysis of the narratives allowed the identification of identities in an environment of rapid changes, with a multiplicity of individuals, where the identity constructions are not unified, but are always in transformation.

Keywords: Narratives; Identities; Discourse; Migration process.

\section{Introdução}

O presente trabalho fundamenta-se na análise de narrativas como um modo básico de compreensão e compartilhamento de experiências e considera esse tipo de produção discursiva uma prática social envolvida intrinsecamente na constituição e na manutenção das relações sociais de uma comunidade. O campo dos estudos narrativos é amplo e interdisciplinar, uma vez que desperta o interesse não só dos linguistas, mas também de teóricos literários, psicólogos sociais, sociólogos, historiadores, especialistas em comunicação, cada vez mais interessados nesse formato discursivo, em face da multiplicidade de recursos e aspectos situacionais empreendidos.

Considerando que as narrativas e as identidades emergem nas diversas interações cotidianas ou institucionais, sendo a discursividade uma lente privilegiada para investigar as práticas sociais e experiências pessoais (BASTOS, 2007; BASTOS; SANTOS, 2013), a presente pesquisa de caráter interpretativo/qualitativo tem como tema central o processo de construção de identidades da comunidade de Balsas, cidade do Sul do Maranhão, que vivenciou um processo recente de migração que culminou em mudanças de sua territorialidade e no desenvolvimento agrícola da região. Conhecer as identidades que emergem nesse processo histórico em uma região marcada por diferentes ciclos migratórios, em um contexto recente, significa dar voz aos participantes dessa inter-relação de circunstâncias como protagonistas de suas histórias.

Este artigo pretende trazer à discussão a migração não do ponto de vista do migrante, mas das pessoas que nasceram na região e viveram intensamente as consequências do processo migratório. Ao contrário da 
maioria dos estudos sobre migração que se centram nas histórias dos migrantes, nosso foco de análise recai nas comunidades formadas que emergiram das transformações ocorridas na região, a partir de narrativas das pessoas que já viviam no local com sua cultura e seus costumes. Por esse viés, o objetivo deste trabalho é investigar como as identidades são construídas interacional e textualmente nas narrativas, e o intuito de nosso empreendimento analítico é analisar os fenômenos linguísticos e identitários que emergem nas narrativas desses atores sociais.

Para alcançarmos tal objetivo, o nosso arcabouço teórico e metodológico está ancorado no campo de estudos das narrativas orais e nos estudos da análise da conversação de orientação textual-interativa. A escolha por integrar esses dois campos nos proporciona categorias teóricas e analíticas que abarcam a dimensão discursiva das histórias orais e os aspectos textuais-interativos de constituição do texto oral na interação. Isso nos possibilita abordar as narrativas orais como um locus privilegiado para investigar a natureza linguístico-discursiva, bem como fenômenos de ordem social e semântica imbricados no entendimento das relações entre linguagem e organização social.

O contexto escolhido, a cidade de Balsas, no Sul do Maranhão, deuse em decorrência do intenso progresso ocorrido a partir de 1970 quando a região se transformou em um importante polo agrícola. $\mathrm{O}$ desenvolvimento do agronegócio atraiu uma quantidade expressiva de trabalhadores que partiram de diversas regiões do país em busca de melhores condições de vida, principalmente agricultores sulistas em busca de um pedaço maior de terra para plantar.

Os discursos construídos especificamente pelos participantes que nasceram em Balsas remetem às suas histórias e a de migrantes que se estabeleceram em uma nova região, em que as redes de trabalho e os estilos de vida do local são recriados e modificados no novo mundo, vistos sob o olhar do homem natural da região, envolvido diretamente nesse processo. Evidentemente, a experiência de um grupo étnico particular no local de destino é um elemento necessário à história da migração, pois as mudanças no interior de comunidades étnicas estabelecidas e relações de contestação à cultura dominante são frequentemente motivações para o registro de histórias da chegada de migrantes, mas também das pessoas que já viviam no local com sua cultura e seus costumes 
As narrativas que integram o corpus em análise foram geradas a partir de entrevistas orais em que emergem narrativas de histórias de vida. Nesse tipo de produção discursiva, os participantes constroem o seu universo social onde os papéis sociais são estabelecidos e relacionados ao tempo/espaço da migração e às mudanças sociais da região sul maranhense. Por essa perspectiva, consideramos que as narrativas possibilitam investigar os fenômenos linguísticos que estão diretamente ligados à construção do discurso do sujeito sócio-histórico. E é nesse sentido que são usadas estratégias de referenciação, por meio das quais os narradores constroem textual e discursivamente a categorização ou recategorização dos referentes nas narrativas.

Compreendida a partir de seu caráter interativo, a narrativa apresenta traços linguísticos que se revelam na interação, como elementos da materialidade linguística da construção do texto oral. Em função disso, mobilizaremos a noção de referenciação como uma categoria teóricoanalítica para demonstrar os processos de construção identitária que emergem nas narrativas de histórias de vidas analisadas neste artigo.

\section{As Narrativas e as Construções Identitárias}

A prática de contar histórias é própria do ser humano no que tange à sua natureza de se organizar em grupos sociais. A todo o momento, contamos e ouvimos histórias que nos cercam, permeiam as nossas vidas desde as mais tenras histórias de uma criança até as palavras sábias e carregadas de experiência dos anciãos. Segundo Johnstone (2001), a narrativa constitui uma prática universal que nos permite construir o sentido de nós mesmos como indivíduos e como membros de uma sociedade. As histórias, dramas e relatos históricos enfatizam as intenções e as ações humanas que são formas de usar a linguagem ou outro sistema simbólico para costurar eventos da vida em uma ordem lógica e temporal, para desmistificá-los e estabelecer coerência, por meio da experiência passada, presente ou ainda não realizada. (BRUNER, 1987).

Partindo do princípio de que todas as pessoas têm uma história para contar, os membros de uma comunidade, ao experienciarem o ato de narrar, constroem-se a si mesmos e dão sentido ao mundo a sua volta. Nessa perspectiva, é possível considerar que as narrativas orais são o resultado das experiências de ações vivenciadas pelas pessoas, com maior ou menor grau de detalhes, pois o ato de narrar também permite 
aos sujeitos narradores a manutenção da memória de suas experiências e a história de suas comunidades. (DE FINA; GEORGAKOPOULOU, 2012).

Verdadeiras ou ficcionais, as narrativas nem sempre representam a verdade, mas são construídas a partir da subjetividade do narrador, da sua visão de mundo e de sua trajetória, pois “[...] cada sujeito, ao narrar sua trajetória de vida, revela-se uma testemunha e um artífice da história" (PERAZZO, 2015, p. 123). Investigar as narrativas pessoais orais possibilita estudar não apenas os constituintes estruturais das histórias, como nos moldes canônicos de Labov (1997), mas, sobretudo, como essa prática constitui um locus que se constitui como:

[...] um instrumento através do qual as pessoas atribuem unidade e coerência à sua existência, e o estudo de como as pessoas costuram elementos dispersos para realizar essa construção pode ajudar na compreensão de como essas produções dão forma ao significado da existência humana no âmbito pessoal e coletivo em vários contextos sociais (BASTOS; SANTOS, 2013. p. 27).

Nesse tipo de pesquisa, o contexto micro torna-se pesquisável e o discurso transforma-se em um objeto privilegiado de pesquisa social, considerando a pesquisa narrativa uma forma de compreensão acerca das experiências humanas. Talvez, isso explique o aumento do interesse pelas histórias em situação de entrevista com o intuito de compreender não apenas o sentido que os indivíduos fazem de si mesmos, como também sua compreensão do mundo e de suas experiências nesse mundo (BASTOS, 2007).

O processo de investigação das entrevistas narrativas revela também um pesquisador que não é neutro, sempre atento à complexidade do que é investigado e que interage na construção narrativa do entrevistado para analisar e compreender melhor a experiência como é contada. Abordagens mais recentes de análise de narrativas começaram a dar mais relevo ao contexto onde essa prática discursiva ocorre. De Fina e Georgakopoulou (2012) argumentam que a história não é apenas uma fabricação do passado, mas uma fronteira entre presente e passado; é um trabalho de memória com restrições no presente interacional. Enquanto as narrativas (por mais breves) dependem das estruturas de 
memória que fazem parte das condições da capacidade de comunicação, há também a questão de como o momento de interação empurra a memória para ser ativada em uma determinada direção.

Adentrar no campo da investigação narrativa é estabelecer que ela é constituída e organizada textualmente e discursivamente como uma prática social e pode nos levar a compreender questões de poder, ideologia e identidade tanto nos ambientes institucionais e cotidianos como no contexto da pesquisa. Os formatos discursivos dentro de uma comunidade linguística refletem aspectos da nossa realidade social e cultural, seja pelas marcas linguísticas comuns a determinados grupos ou pelas relações entre identidades e processos narrativos.

Seguindo o pressuposto de que as práticas diárias de narrativas possibilitam diretamente aflorar as características identitárias, essa pesquisa assume uma perspectiva interpretativista baseada no domínio dos processos de construção identitária a partir de narrativas orais, em que os narradores se assumem como sujeitos e cabe a eles a definição de suas histórias em que suas identidades vão sendo construídas e transformadas. Nesse aspecto, a construção discursiva das identidades assume o papel de compreensão e compartilhamento de experiências individuais ou coletivas, essenciais para transmitir valores morais e normas sociais como é o caso das sociedades construídas a partir dos processos migratórios.

Segundo Silva (2000, p. 75), as identidades são o resultado de atos de criação linguística, "não são coisas que estejam simplesmente aí, à espera de serem reveladas ou descobertas, respeitadas ou toleradas", elas não são do mundo natural, elas precisam ser construídas no contexto de relações culturais e sociais. Com a globalização, as identidades tornaram-se híbridas em um processo de construção incessante. Segundo Hall (2006, p. 7) "as velhas identidades, que por tanto tempo estabilizaram o mundo social, estão em declínio, fazendo surgir novas identidades e fragmentando o indivíduo moderno, até aqui visto como sujeito unificado". O autor explica que somos sujeitos humanos e são tantas as transformações pelas quais passamos que nossas identidades pessoais se modificam sem percebermos, abalando a ideia que temos de nós próprios como sujeitos integrados. As sociedades da modernidade são caracterizadas pela "diferença"; elas são atravessadas por diferentes divisões e antagonismos sociais que produzem uma variedade de diferentes "posições de sujeito", isto é, 
identidades, para os indivíduos.

Na compreensão de Gee (2001), não se pode ter uma identidade de qualquer tipo sem algum sistema interpretativo que subscreva o reconhecimento dessa identidade. $\mathrm{O}$ sistema interpretativo pode ser a visão histórica e culturalmente diferente das pessoas sobre a natureza; pode ser as normas, tradições e regras das instituições; pode ser o discurso e o diálogo dos outros; ou pode ser o funcionamento de grupos de afinidade. As identidades são construídas dentro e não fora dos discursos, e têm a ver de onde nós viemos, mas muito mais com a questão quem nós podemos nos tornar, como nós temos sido representados e como essa representação afeta a forma como nós podemos representar a nós próprios (HALL, 2012).

As narrativas orais, que emergem nas práticas cotidianas de uso da linguagem, revelam que o falante relaciona diferentes contextos, insere a narrativa com propósito planejado, articula várias "camadas" e "cenários" (CLARK, 1996), seu conhecimento de mundo e enciclopédico com os conhecimentos do interlocutor, além das estratégias de referenciação que estabelecem, muitas vezes, os traços de identidade entre os interlocutores. Partindo dessa perspectiva, postulamos que a referenciação desempenha o papel de construção da identidade negociada entre os falantes em nível micro, dentro da atividade narrativa, sendo um fenômeno semântico e discursivo imbrincado no ato de contar histórias.

\section{A Dimensão Textual das Narrativas: A Referenciação}

Para Lopes e Bastos (2002), as narrativas desempenham um papel importante na construção de identidades sociais, pois as pessoas relatam a vida social e, em tal engajamento discursivo, constroem-se e constroem os outros. Essa abordagem leva a discussões fomentadas pela Linguística Textual, que se baseia em uma perspectiva construcionista de atores-sociais que visa a investigar a elaboração das narrativas a partir dos mecanismos de constituição do texto oral, examinando o desenvolvimento das histórias e as coconstruções sociais na interação. (LINDE, 1993). A perspectiva textual-interativa e a noção de referenciação podem agregar ao campo de estudos da narrativa oral um enfoque mais abrangente dos elementos textuais envolvidos na construção da história e no posicionamento de narradores e personagens em narrativas que emergem em um contexto interacional. 
A noção de referenciação representa um deslocamento da clássica questão da referência, por considerar que os processos semânticos não são frutos apenas de uma relação entre as palavras e as coisas, que a construção de referentes no discurso não ocorre somente pela seleção de objetos definidos a priori no uso da linguagem. Pelo contrário, é durante o desenvolvimento da atividade discursiva que emergem os objetos a que o próprio discurso remete (MONDADA; DUBOIS, 2014). Os "objetos de discurso não preexistem naturalmente à atividade cognitiva e interativa dos sujeitos falantes, mas devem ser concebidos como produtos - fundamentalmente culturais - desta atividade" (APOTHÉLOZ; REICHLER-BÉGUELIN, 1995, p. 134).

Conforme afirma Marcuschi (2001), a referência poderia ser tida como aquilo que, na atividade discursiva e no enquadre das relações interpessoais, é construído num comum acordo entre os atores sociais envolvidos numa dada tarefa comunicativa. Nessa perspectiva, "a referenciação na relação face a face é fruto de uma atividade colaborativa e não uma simples convenção linguística" (2001, p. 37). O argumento do autor encontra ressonância em Koch (2008) na medida em que, para a autora, a referenciação está diretamente ligada ao sentido do texto, é construída dentro de uma unidade discursiva e tem um importante papel na construção dos objetos de discurso que compõem a realidade social.

Os objetos de discurso são constituídos na e pela atividade interativa, seja ela por meio de textos escritos, orais ou na conversação face a face, sendo dinâmicos e passíveis de serem (re) configurados semântica e discursivamente. De acordo com Mondada (1997 apud $\mathrm{KOCH}, 2004$, p. 79), o objeto de discurso:

$\begin{aligned} & \text { caracteriza-se pelo fato de construir } \\ & \text { progressivamente } \\ & \text { enriquecendo-se com novos } \\ & \text { configuração, } \\ & \text { aspectos e }\end{aligned}$
propriedades, suprimindo aspectos anteriores ou
ignorando outros possíveis, que ele pode associar
com outros objetos ao integrar-se em novas
configurações, bem como articular em partes
suscetíveis de se autonomizarem por sua vez em
novos objetos. O objeto se completa
discursivamente.


A noção de objetos de discurso rompe com a concepção da linguagem ser apenas uma forma de nominalizar, de "etiquetar" os objetos no mundo, por situar a linguagem, e as atividades de significação como uma atividade cognitiva e social que constitui a realidade humana. Conforme Koch (2008, p. 101), "os objetos de discurso são dinâmicos, isto é, uma vez introduzidos, vão sendo modificados, desativados, reativados, recategorizados, de modo a construir-se ou reconstruir-se o sentido no curso da progressão textual". Em consonância com a perspectiva textual-interativa, a autora acrescenta que a referenciação tem sido entendida como uma atividade discursiva, ou seja, como um processo constituído na atividade discursiva e que resulta na construção de objetos de discurso, elementos cruciais na produção dos sentidos do texto (MIRA; CARNIN, 2017). Koch (2016) apresenta o estudo das atividades discursivas e de suas materialidades linguísticas denominando-o como "estratégias de referenciação", uma reativação dos referentes no texto, formando, dessa maneira, uma cadeia coesiva que retoma temáticas que percorrem a narrativa inteira. Com efeito, essa (re)ativação dos referentes pode ocorrer a partir de expressões nominais ou descrições definidas que implicam na escolha de qualidades que caracterizam o referente de acordo com qualidades ou propriedades que, em dadas situações de interação, fazem parte dos propósitos a serem atingidos.

$\mathrm{Na}$ perspectiva de adequação referencial, apresentam-se variações das categorizações referenciais no discurso. Dessa forma, esse estudo propõe-se a avaliar como os sujeitos, atores-sociais, utilizam os procedimentos linguísticos dentro de um contexto, considerando a referência aos objetos do mundo psíquico e natural como um processo de categorização discursiva e cognitiva tal como são observados nas práticas situadas dos sujeitos. Assim, as atividades de categorização e referenciação passam a ser encaradas como uma dimensão discursiva, desenvolvendo uma perspectiva de que o estabelecimento do sentido não se dá a priori, mas sim na interação.

A articulação entre a noção de referenciação, a construção de narrativas e as identidades constituem o alicerce teórico desta investigação que se caracteriza como pesquisa social, em que estamos interessados na maneira como as pessoas espontaneamente se expressam e falam sobre o que é importante para elas e como elas pensam sobre suas ações e as dos outros. 


\section{Construtos Metodológicos}

O presente trabalho centra-se na análise interpretativista da linguagem e, por meio das produções discursivas dos sujeitos participantes, pretende revelar subjetividades e sentidos expressos no mundo coconstruído na ação de narrar. A abordagem teórico-analítica a ser utilizada é a análise das narrativas orais (BASTOS; SANTOS, 2013; DE FINA; GEORGAKOPOLOU, 2012), tendo como categorias de análise o conceito de identidades (HALL, 2006;) e a noção de referenciação (KOCH, 2005, 2008; MARCUSCHI, 2003; MONDADA; DUBOIS, 2014).

A presente pesquisa é de natureza qualitativa, assumindo uma perspectiva em que as identidades vão sendo construídas e produzidas na interação face a face. Nesse sentido, a entrevista narrativa passa a ser compreendida como uma performance situada (MISHLER, 1999) em que o narrador "lida com as circunstâncias da situação e a estrutura social normativa" (BASTOS; SANTOS 2013, p. 121). É nesse movimento de performance narrativa que personagens, ações e o mundo narrado são tecidos e postos em relação a quem produz e ouve histórias. Portanto, o narrador, o participante da pesquisa, não é visto como a fonte de informações a serem objetivamente coletadas e analisadas, mas como alguém que coconstrói com o entrevistador o discurso produzido na situação de entrevista; situação essa que se faz cada vez mais presente na vida social contemporânea (BASTOS; OLIVEIRA, 2012).

O contexto de geração de dados deste trabalho é a cidade de Balsas, no Sul do Maranhão, hoje importante polo agrícola exportador de grãos, que recebeu uma intensa leva de migrantes a partir de 1970 e que suscita investigações acerca das (re)construções identitárias surgidas a partir desse processo. Tais processos históricos, movimentos migratórios e transformações estruturais da sociedade, particularmente relações entre longos meios de redistribuição da população e das atividades econômicas, constituem um locus interessante para análise de processos identitários dos atores sociais desse processo de migração.

Gaúchos, paranaenses, catarinenses, paulistas, mineiros, goianos, mato-grossenses, dentre outros, e, sobretudo, nordestinos, migraram para a região, por vários motivos, principalmente em busca de qualidade de vida e oportunidades de trabalho. Acontece, então, uma 
sobreposição com os que já estavam ocupando o espaço com suas tendências culturais já enraizadas. Os hábitos, costumes e estilos de vida na "Amazônia Nordestina" então passam por um grande processo cultural de adaptação, mudança e transformação, num processo de integração regional, moldando essa nova fronteira no Sul do Maranhão.

A geração de dados foi por meio de entrevistas semiabertas em que os participantes eram estimulados a contar suas histórias de vida relacionando-as com os acontecimentos históricos da cidade e a sua posição diante do processo migratório. As entrevistas foram iniciadas a partir de perguntas sobre os fatos da região, a memória do processo migratório, o tempo de permanência e convívio na cidade de Balsas. Os encontros foram gravados em meio audiovisual para que fosse garantida uma observação mais detalhada dos dados. O sistema de notação utilizado na transcrição dos dados tem como base as notações já utilizadas nos estudos do projeto NURC (Norma Urbana Culta) e marcações propostas no trabalho de Marcuschi (2003) e adaptado pelo modelo de transcrição utilizado pelo grupo de pesquisa "Narrativa, Interação e Linguagem”, vinculado ao Programa de Pós-Graduação em Linguística Aplicada da Universidade do Vale do Rio dos Sinos (UNISINOS).

Em cada entrevista foi apresentado o Termo de Consentimento Livre e Esclarecido (TCLE) em que os participantes foram informados que poderiam desistir de participar da pesquisa, mesmo depois dos dados terem sido gravados para preservar a identidade e o anonimato dos mesmos durante todo o processo de coleta e transcrição. A pesquisa foi aprovada pelo Comitê de Ética da Universidade do Vale do Rio dos Sinos, protocolo $\mathrm{n}^{\circ} \mathrm{n}^{\circ} 2.047 .64 / 2017$.

Tendo em vista o contexto empírico da pesquisa, esclarecemos que este artigo é um recorte da tese de doutoramento sobre as identidades construídas pelos balsenses em suas histórias de vida, em que participaram oito sujeitos escolhidos pelos seguintes critérios: a) sujeitos nascidos em Balsas no Maranhão; b) residentes na zona urbana e na zona rural; c) conhecedores da história de Balsas e a trajetória de suas famílias; d) nível de escolaridade e e) profissão.

A escolha da narrativa aqui analisada, do participante Luís, segue os critérios acima, além de apresentar a recorrência de narrativas autobiográficas nas entrevistas, o pertencimento à comunidade e as mudanças significativas ocorridas em decorrência do processo 
migratório. Essa escolha deve-se à necessidade de imersão em aspectos complexos da temática, possibilitando compreender elementos subjacentes aos discursos dos sujeitos quando constroem e partilham suas narrativas.

\section{Análise Discursiva da Narrativa}

No conjunto de narrativas analisadas que compõem o corpus desta pesquisa, o narrador constrói suas histórias recorrendo a determinados recursos temáticos, enunciativos que marcam a constituição textual e discursiva da narrativa oral. É nesse domínio empírico que procuramos mostrar as estratégias referenciais implicadas na construção de objetos de discurso que se constitui como o fio condutor dos processos de entrosamento e colaboração entre os falantes, que procuram articular suas falas, mantendo-as, de forma coesa e coerente, em torno de um conjunto referencial que se projeta como foco da interação em dado momento do evento comunicativo (JUBRAN, 2006).

Por isso, consideramos que as práticas conversacionais se constituem em torno dos fatores de ordem semântica e pragmática que mantêm o envolvimento da conversação. Atribuímos aos fenômenos de desenvolvimento do tópico discursivo o caráter de organização da conversação, de constituição do contexto interativo, e, também de definição das formas de construção colaborativa de objetos de discurso por meio de operações linguístico-cognitivas realizadas pelos sujeitos em interação.

Em sua entrevista, Luís apresenta-se como balsense nascido a $20 \mathrm{~km}$ da cidade, tem 42 anos e veio muito cedo do sertão com os pais e oito irmãos, depois eram 10. O participante conta a história de seus avós que, como a maioria dos balsenses, vieram de outros estados como Piauí e Bahia e, quando chegaram à cidade, depararam-se com poucas famílias tradicionais, ricas que contrastavam com a grande maioria que vivia em torno que eram os mais pobres, sem o mínimo de condições de sobrevivência, sem energia, sem água, sem trabalho. A família "inventou um modo de sobreviver", o pai vendia frutas na feira, e a mãe, bolo e cuscuz. Desde criança, junto com os irmãos, ajudava a mãe na feira e no mercado público todos os dias até a hora de ir para a escola e, à tarde, vendia "dindim" para ajudar nos gastos da casa.

É por meio dessas localizações identitárias que Luís abre sua narrativa. 


\begin{tabular}{|c|c|c|}
\hline $\begin{array}{ll}9 \\
10 \\
11 \\
12\end{array}$ & Luís & $\begin{array}{l}\text { bom... então você já falou eu sou luís e sou balsense } \\
\text { e nasci a uns } 20 \mathrm{~km} \text { da cidade... nasci no município de } \\
\text { Balsas aos uns } 20 \mathrm{Km} . . \text { aqui da sede do município... } \\
\text { é:: num povoado... ou melhor... num lugar... numa } \\
\text { morada... lá não era um povoado... que se chama } \\
\text { BREJo... fica direção de... da Santa Maria... por } \\
\text { ali... e: como é que eu nasci... eu nasci ali e com } 8 \\
\text { anos nós já viemos para Balsas... Eu cheguei em Balsas } \\
\text { aqui na cidade com } 8 \text { anos... então tenho } 40 \text { e: hoje } 42 \\
\text { anos de município... de sede do município... }\end{array}$ \\
\hline $\begin{array}{l}73 \\
74 \\
75\end{array}$ & Luís & $\begin{array}{l}\text { que é suquinho pra nós... então é: : a minha mãe deixou } \\
\text { uma herança muito valiosa pra todos nós meus } \\
\text { irmãos...que foi ensinar a gente a trabalhar... }\end{array}$ \\
\hline 76 & Marta & quantos irmãos... \\
\hline $\begin{array}{l}77 \\
78 \\
79 \\
80 \\
81 \\
82 \\
83 \\
84 \\
85 \\
86 \\
87 \\
88\end{array}$ & Luís & $\begin{array}{l}\text { nós somos } 10 \ldots . .10 \text { irmãos... é: ... então foi assim... } \\
\text { fomos chegando aqui e tentar estudar... e depois eu } \\
\text { acho que convivi... dentre esses } 42 \text { anos aqui na sede } \\
\text { do município com essa... eu percebi... eu consegui } \\
\text { conviver com: assistir melhor dizendo essa... essa } \\
\text { evolução... ou seja... essa ... esse crescimento do } \\
\text { município... essa mistura que cada ano que ia passando } \\
\text { isso ia acontecendo cada vez mais... porque eu acho } \\
\text { que pra gente chegar a compreender hoje tentar fazer } \\
\text { esse esforço pra compreender essa cidade hoje... g gente } \\
\text { precisa saber de tudo isso... de quem tá aqui } \\
\text { hoje...veio de onde e por que veio.. }\end{array}$ \\
\hline
\end{tabular}

Imagem 1: Excerto 1 - A construção do "eu" individual e coletivo

No excerto 1, o recorte entre os turnos foi utilizado para destacar as sequências narrativas que contribuem para a construção da identidade do participante. $\mathrm{Na}$ linha 9, o tópico da narrativa se organiza a partir da origem de Luís onde podemos destacar a presença do dêitico pessoal "eu", que favorece a identificação do falante, neste caso, inserindo-se como "balsense". Os turnos 10, 11 e 12 mostram a relação de pertencimento à comunidade de Balsas pelas recategorizações de seu local de nascimento, que especificam o fato de "ter nascido no munícipio de Balsas a uns 20 km”. As predicações valorativas em uma escala do maior para o menor do lugar de nascimento (povoado, lugar e morada) marcam uma escala de qualificação de que Luís é balsense, apesar do local de nascimento ser um lugar diferente e com organização territorial e geográfica menor que a cidade. No segmento 16-18, é possível observar que Luís se posiciona na narrativa como narrador/personagem que passou a maior parte da vida, quarenta de seus quarenta e dois anos em Balsas, portanto alguém que se mostra inserido no lugar, confirmando a relação de pertencimento ao utilizar o referente "então tenho... hoje 40 anos de município... de sede do município....". 
O uso da primeira pessoa como recurso linguístico para se posicionar no universo do relato é a recapitulação oral de histórias vividas pessoalmente no cotidiano. Podemos constatar, nas linhas 7375, que o ato de narrar sobre si mesmo é claramente constitutivo de identidades individuais e coletivas: “...a minha mãe deixou uma herança muito valiosa pra todos nós meus irmãos, que foi ensinar a gente a trabalhar". A forma como Luís se posiciona no universo narrativo possibilita que assuma o seu papel desempenhado no contexto social de que faz parte. Na linha 82, Luís se posiciona como sujeito que viveu e presenciou as mudanças ocorridas. Apresenta, na narrativa, o sintagma nominal (SN) "essa evolução..." constitui uma estratégia discursiva denominada parentização, que tem por característica a inserção, no segmento tópico, de informações de relevância sobre o ato verbal em curso. Segundo Jubran (2006), esse fenômeno traz para dentro do texto explicitações sobre a situação enunciativa que tem implicações sobre a significação dos enunciados tópicos vizinhos. Luís define referencialmente o que é assistir às modificações ocorridas no município, cuja função de especificação, além de trazer um maior refinamento da categorização, nomeia o referente e lhe confere relevância positiva, permitindo que o sujeito introduza elementos avaliadores à sua fala, contribuindo para uma orientação argumentativa do texto.

As retomadas na narrativa que contribuem para a coesão e, também, para a progressão do texto, são em geral asseguradas por um conjunto de dispositivos linguísticos intimamente ligados não só ao aspecto de construção/continuidade do sentido, mas também ao da dinâmica textual. Esse é um mecanismo anafórico e se caracteriza como uma expressão referencial que pode ser sempre substituída por uma outra expressão, desde que esta última identifique, designe, evoque ou convoque o referente antecedente. Na linha 82 "esse crescimento" e na linha 83 "essa mistura" caracterizam uma retomada do referente "evolução" evidenciando uma anáfora para recategorizá-lo e especificá-lo. A propriedade de retomar permite a continuidade de um núcleo referencial com a forma nominal "tudo isso" que encapsula, sumariza um único rótulo para todos os referentes enunciados anteriormente. Luís menciona que Balsas é uma "mistura" de tantas pessoas vindas de diversos lugares e para entender esse processo, caracterizado pela expressão nominal "hoje", é preciso conhecer como 
aconteceu essa sequência de fatos ocorridos no decorrer do tempo para assim entender o presente.

$\mathrm{Na}$ linha 84, quando Luís aciona a primeira pessoa, faz uma analogia entre a sua evolução pessoal e o progresso da cidade, ocorrendo uma recategorização em que vai analisando o avanço da cidade. Isso fica expresso no trecho "... porque eu acho que pra gente chegar a compreender hoje... tentar fazer esse esforço pra compreender essa cidade hoje... a gente precisar saber de tudo isso...". O “eu” expresso por Luís faz com que se privilegie e valorize a história individual, mas também o processo do outro como elemento fundamental para uma elucidação ou até uma redefinição da identidade individual e coletiva da cultura em que se encontra inserido.

Narrar não é somente relatar eventos passados, mas sim resgatar e construir no discurso as experiências vividas. Nesse sentido, as histórias contadas configuram-se como um exercício interpretativo-identitário que comporta não somente as apropriações do contexto como também as experiências e posições assumidas pelo sujeito. Nessa perspectiva, tais sujeitos se tornam sujeitos da história porque, no momento da (re)construção, eles atribuem sentidos próprios à história social da região em função de suas próprias experiências culturais. As identidades sociais vão emergindo nesse contexto de depoimento como um modo de compreensão de si e da realidade social.

Um grande impacto ocorrido na região pesquisada, talvez o mais marcante, foi a intensa migração a partir da década de 70 , intensificando-se nas décadas posteriores, quando famílias inicialmente oriundas do Rio Grande do Sul, depois de outros estados migraram para a região e começaram a explorar as chapadas balsenses, áreas até então consideradas improdutivas pela população local.

Em associação ao processo de ampliação da sojicultura, ocorreram significativas mudanças sociais, econômicas, políticas e ambientais. As migrações ocorreram devido ao incentivo de Programas do Governo para desenvolver a região e por vários motivos como busca de qualidade de vida e oportunidades de trabalho e educação. 


\begin{tabular}{|c|c|c|}
\hline $\begin{array}{l}186 \\
187 \\
188 \\
189 \\
190 \\
191 \\
192 \\
193\end{array}$ & Marta & $\begin{array}{l}\text { e Luís essa questão dos migrantes que começaram a vinda } \\
\text { a partir de } 70 \ldots \text { primeiro vieram os gaúchos e depois } \\
\text { pessoas do mundo inteiro... porque tem estrangeiros } \\
\text { aqui né... como é que você vê esse impacto assim... você } \\
\text { falou um pouquinho da natureza... que você é defensor da } \\
\text { natureza nas suas músicas... como você vê essa questão } \\
\text { do impacto... ela foi mais positiva ou ela foi mais } \\
\text { negativa... como é que você vê isso? }\end{array}$ \\
\hline $\begin{array}{l}194 \\
195 \\
196 \\
197 \\
198 \\
199 \\
200 \\
201 \\
202 \\
203 \\
204 \\
205 \\
206\end{array}$ & Luís & $\begin{array}{l}\text { eu acho é... ela tem dois... duas vertentes... dois } \\
\text { olhares... eu olho pra esse impacto aí... essa presença } \\
\text { do: é: do pessoal de fora que chegaram em torno do } \\
\text { agronegócio... os dois: : o positivo é que você... se } \\
\text { você for olhar como vivia a população antes era uma outra } \\
\text { coisa... não existia trabalho... quer dizer trabalho } \\
\text { sim... mas não existia emprego como toda essa chegada } \\
\text { que o agronegócio proporcionou... entendeu? e } \\
\text { consequentemente isso impulsionou as autoridades... o } \\
\text { próprio lugar a ir atrás de meios... de escolaridade que } \\
\text { não existia praticamente quase nada... então toda essa } \\
\text { relação de: trabalho entre empregado e empregador mudou } \\
\text { certa contribuição porque também o povo veio com. }\end{array}$ \\
\hline $\begin{array}{l}222 \\
223 \\
224 \\
225 \\
226 \\
227 \\
228 \\
229 \\
230 \\
231 \\
232 \\
233 \\
234 \\
235 \\
236 \\
237 \\
238\end{array}$ & & $\begin{array}{l}\text {...nesse sentido houve essa contribuição... houve a } \\
\text { contribuição com a mudança de mentalidade das pessoas } \\
\text { locais... então nesse aspecto... tem o outro que eu acho } \\
\text { que é mais negativo que é essa forma de ser... esse ar } \\
\text { de ser colonizador... entendeu? que não eram só os que } \\
\text { já moravam aqui... quem veio de fora é como se chegasse } \\
\text { numa aldeia de índio e chega nesse ar de colonizador que } \\
\text { vem com uma nova forma... um novo jeito... "que esse } \\
\text { povo aqui não sabe fazer nada e assim que tem que ser a } \\
\text { coisa"... então houve muito ...mas muito isso... e aliás } \\
\text { ainda é hoje existe isso entendeu? e alguns } \\
\text { relacionamentos a gente percebe o ar de colonizador de } \\
\text { chegar e querer colonizar... querer mostrar o que... } \\
\text { como algumas pessoas dizem o... o nativo não sabe de } \\
\text { nada... vamos implantar... essa coisa do jeito de ser } \\
\text { colonizador... isso é muito... isto também é muito do } \\
\text { Europeu... }\end{array}$ \\
\hline $\begin{array}{l}253 \\
254 \\
255 \\
256 \\
257 \\
258\end{array}$ & Luís & $\begin{array}{l}\text { do pessoal do: : esses cury que chegaram... que eles são } \\
\text { pessoas... que tiveram uma gran: de influência na } \\
\text { cidade... chegaram a ser prefeitos... vereadores... eles } \\
\text { tiveram grande influência política mesmo na forma de: } \\
\text { trabalhar... de formar o povo... eles tiveram grande } \\
\text { influência... essa aí foi... você lembrou muito }\end{array}$ \\
\hline
\end{tabular}

Imagem 2: Excerto 2 - $\mathrm{O}$ pertencimento frente às mudanças

Em relação aos pontos de vista externados, por meio do emprego de processos referenciais, observa-se que vão do positivo ao negativo, e, por vezes, mesclam os dois. Quando Marta pergunta a Luís sobre os impactos ocorridos com a chegada das pessoas "de fora", Luís caracteriza o impacto por meio de cadeias referenciais anafóricas nas linhas 194-195 "duas vertentes... dois olhares...", facilmente identificáveis pela relação direta que uma tem com a outra.

Segundo Cavalcante et al. (2011), o fenômeno da referenciação não 
se limita somente à retomada dos elementos linguísticos explicitados no contexto, mas está condicionado a regras sociais de cada comunidade. Luís, na sua construção, apresenta uma informação específica fornecida no contexto linguístico que foi a relação de trabalho, em que as pessoas recebiam salários irrisórios que não condiziam com o restante do país, desde professor a diaristas e assalariados na linha 205: "essa relação de:: trabalho entre empregado e empregador", o que abala as relações de trabalho existentes na região é caracterizado positivamente na linha 222: "nesse sentido houve essa contribuição...".

Na linha 225-226: "eu acho que é mais negativo que é essa forma de ser... esse ar de ser colonizador..." Luís aciona o referente anafórico "colonizador" em um processo de recategorização denominado rotulação por meio de novas predicações atributivas que delineiam a imagem daquele que é enviado para colonizar, habitar determinado lugar ou região. Luís reporta-se a colonizador quando nas linhas 227 229 refere-se a "quem veio de fora é como se chegasse numa aldeia de índio", fazendo uma relação própria do colonizador que acha que as pessoas não sabem fazer nada, reproduzindo a ideia equivocada de que as culturas indígenas eram atrasadas e primitivas. Nas linha 234-236: "querer colonizar... querer mostrar o que... como algumas pessoas dizem o... o nativo não sabe de nada...", ao utilizar o referente "nativo", Luís aciona uma estratégia discursiva em que o objeto-de-discurso designado pela descrição foi caracterizado para indicar aquilo em que consiste verdadeiramente este objeto. Para os balsenses, "nativo" remete a índio, uma expressão rotuladora que se reporta a uma interpretação ancorada no contexto. Os balsenses não aprovam ser rotulados de nativos, mas, sim, de sertanejos que remete a ser forte, guerreiro e integralmente associados a terra.

As migrações sempre existiram, pois os homens historicamente sempre se deslocaram. Em cada época da história, contudo, elas são diferentes nas causas que as motivam, nas modalidades dos deslocamentos, nas implicações, no significado que lhes atribuem e nas consequências tanto entre quem se desloca quanto entre aqueles que os acolhem. Segundo Hall (2012), a identificação é construída a partir do reconhecimento de alguma origem comum, ou de características que são compartilhadas com outros grupos ou pessoas, ou ainda, a partir de um mesmo ideal. 
A análise de construções narrativas nos possibilita tecer relações sociais e apresenta um sujeito narrador que exerce a sua cultura e cria identidades sociais por meio das narrativas que relata, possibilitando um sentimento de pertença frente ao processo migratório.

Pertencer a um território envolve muito mais do que nascer e morar nele, envolve, acima de tudo, o estabelecimento de relações sociais e a construção de uma identidade regional. Dominar o idioma e criar vínculos sociais não implica, necessariamente, a existência de um sentimento de pertencimento. Esse sentimento também envolve a construção de uma identidade cultural que abrange hábitos, crenças e tradições ligadas ao cotidiano. Penna (1998) explica que o sentimento de pertencimento surge justamente da articulação da união entre a identidade territorial e a identidade cultural. Para Ojima e Fusco (2014), em tempos mais recentes e com a globalização, novos componentes foram acrescentados e temos hoje a possibilidade de nos defrontarmos com culturas híbridas onde há um duplo sentimento de pertencimento, que pauta as relações individuais e coletivas e dá novos contornos à sociedade global.

Assim, a referenciação não se resume apenas a um ato de enunciar por palavras, mas um posicionamento complexo e dinâmico de negociação de objetos de discurso. Este trabalho reforça a existência de uma relação teórica entre referenciação e construção de identidade, uma vez que ambos os fenômenos constituem práticas discursivas praticadas conforme a percepção cultural dos interlocutores em uma determinada situação comunicativa.

\section{Considerações Finais}

O objetivo do presente artigo centrou-se em analisar como as identidades dos moradores nascidos em Balsas no Maranhão são construídas linguística e textualmente em um contexto social específico. Uma região caracterizada pelo encontro de vários povos vindos de muitos lugares mostra-se como um cenário favorável para investigar o processo de construção das identidades que emergiam nas narrativas orais. Para isso propusemo-nos uma análise qualitativa/interpretativista fundamentada em uma abordagem social em que os participantes, por meio de entrevistas narrativas, delinear os caminhos traçados nas histórias contadas e evidenciar as identidades construídas no contexto proposto. 
As bases teóricas de Análise de Narrativas e Identidades e as análises validadas pelos processos propostos pela Linguística Textual possibilitaram uma contribuição relevante para a configuração do objeto de estudo desta pesquisa: o texto oral. As narrativas de histórias de vida refletem o percurso de análise do texto oral, para dele depreender particularidades e mecanismos de estruturação textual específicos. Os traços característicos da oralidade não planejada mostraram-se eficazes no jogo de relações interpessoais para demonstrar o envolvimento dos interlocutores. E mais, as categorias analíticas de natureza textual-discursiva possibilitaram a identificação de unidades textuais, não apenas como uma retomada ou uma categorização, mas como um objeto de discurso presente na memória discursiva ou textual.

A articulação da análise de narrativas com os estudos do discurso e das identidades sociais no âmbito da Linguística Textual possibilitou investigar a construção de sentidos identitários e as consequências do engajamento dessa prática discursiva que é a produção e a interpretação da narrativa.

As identidades são construídas, formadas e transformadas constantemente, mas o contexto desta pesquisa, particularizando o ponto de vista, a visão discursiva do sujeito, faz esta pesquisa ser singular. Pesquisar o não pesquisado, investigar o desconhecido são imprescindíveis para entender os traços identitários.

A medida em que as culturas nacionais, regionais ou locais tornaram-se mais expostas a influências externas, surgiram as identidades partilhadas (HALL, 2012). Em um caráter posicional, a identidade e a diferença foram entrelaçadas, emergindo identidades culturais que não são fixas, mas que estão em transição, entre diferentes posições e novas relações de espaço e tempo. Os posicionamentos construídos na interação permitiram interpretar as identidades sociais que foram sendo construídas discursivamente explicitando o sujeito unitário e aquele modificado por forças externas. Esse processo permitiu que os participantes se constituíssem expondo suas posições em relação a si e aos outros. Essas relações, assim como as identidades, são modificadas conforme a posição social que o narrador assume na interação, por isso são constantemente reposicionadas. O posicionamento nos permite interpretar as identidades sociais discursivamente construídas (LOPES, 2006). 
As questões discutidas possibilitaram corroborar que por meio das narrativas as identidades vão sendo construídas e reconstruídas no discurso. E, também, essa análise possibilitou observar como as identidades são híbridas e estão diretamente relacionadas ao tempo e espaço. O tempo assumido pelo narrador em relação à história contada é determinante para o seu posicionamento e esse contínuo pode levar a instâncias mais profundas da análise. As histórias narradas refletem o mundo, ou as formas como os sujeitos querem ser vistos, viabilizando um universo semântico produzido pela concretude das imagens criadas pela linguagem, considerada aqui, como uma "lente linguística" adequada para investigar a relação entre identidades e processos narrativos.

\section{Referências bibliográficas}

APOTHÉLOZ, D.; REICHLER-BÉGUELIN, M. J. Construction de la référence et stratégies de désignation. In: BERRENDONNER, A.; REICHLER-BÉGUELIN, M. J. (Org.). Du sintagme nominal aux objets-de-discours. Neuchâtel: Université de Neuchâtel, 1995, p. 142173.

BASTOS, L. C. Estórias, vida cotidiana e identidade: uma introdução ao estudo da narrativa. In: CALDAS-COULTHARD, C. R.; CABRAL, L. S. (Org.). Desvendando discursos: conceitos básicos. Florianópolis: Ed. UFSC, 2007, p. 79-111.

BASTOS, L. C.; SANTOS; W. S. A entrevista na pesquisa qualitativa: perspectivas em análise da narrativa e da interação. Rio de Janeiro: 2013, FAPERJ.

BRUNER, J. Life as narrative. Social Research, New York, 1987, v. 54, n. 1, p. 11-32.

CAVALCANTE, M. M. et al. Dimensões textuais nas perspectivas sociocognitiva e interacional. In: BENTES, A. C; LEITE, M. Q. Linguística de texto e análise da conversação: panorama das pesquisas no Brasil. São Paulo: Cortez, 2011, p. 225-261.

CLARK, H. Using Language. New York: Cambridge University Press, 1996.

DE FINA, A.; GEORGAKOPOULOU, A. Analyzing narrative: discourse and sociolinguistic perspectives. Cambridge: Cambridge University Press, 2012. 
GEE, J. P. Identity as an analytic lens for research in education. Review of Research in Education, Itasca, 2001, Ill, v. 25, p. 99-125.

HALL, S. A identidade cultural na pós-modernidade. Rio de Janeiro: DP\&A, 2006.

HALL, S. Quem precisa de identidade? In: SILVA, T. T. (Org.). Identidade e diferença: a perspectiva dos Estudos Culturais Petrópolis: Vozes, 2012, p. 247-264.

JOHNSTONE, B. Discourse analysis and narrative. In: SCHIFFRIN, D.; TANNEN, D.; HEIDI, E. H. (ed.). The handbook of discourse analysis. Malden, Mass.: Blackwell, 2001. p. 635-649.

JUBRAN, C. C. A. S. Revisitando a noção de tópico discursivo. Cadernos de Estudos Linguísticos, Campinas, 2006, v. 48, n. 1, p. 3342.

KOCH, I. G. V. Como se constroem e reconstroem os objetos de discurso. Revista Investigações, Recife, 2008, v. 21, n. 2, p. 99-114. O texto e a construção de sentidos. São Paulo: Contexto, 2016.

KOCH, I. V. G.; MORATO, M. E.; BENTES, A. C. Apresentação. In: KOCH, I. V. G.; MORATO, M. E.; BENTES, A. C. (Org.). Referenciação e discurso. São Paulo: Contexto, 2005, p. 8-10. LABOV, W. Some further steps in narrative analysis. Journal of Narrative and Life History, Hillsdale [New] Jersey, 1997, v. 7, n. 1-4, p. 395-415.

LINDE, C. Life stories: the creation of coherence. New York: Oxford University Press, 1993.

LOPES, L. P. M. Identidades fragmentadas: a construção discursiva de raça, gênero e sexualidade em sala de aula. Campinas: Mercado de Letras, 2006.

LOPES, L. P. M.; BASTOS, L. C. A experiência identitária na lógica dos fluxos-uma lente para se entender a vida social. In: LOPES, L. P. M.; BASTOS, L. C. (Org.). Para além da identidade: fluxos, movimentos e trânsitos. Belo Horizonte: UFMG, 2002, p. 9-23.

MARCUSCHI, L. A. Análise da conversação. São Paulo: Ática, 2003. . Atos de referenciação na interação face a face. Cadernos

de Estudos Linguísticos, Campinas, 2001, n. 41, p. 37-54, jul./dez. MIRA, C.; CARNIN, A. Histórias sobre o convívio com a doença de Alzheimer: contribuições da noção de referenciação para a análise de narrativas no contexto de interações de um grupo de apoio. Caderno 
de Estudos Linguísticos. Campinas, 2017, v. 59, n. 1, p. 157-174, jan./abr.

MISHLER, E. Storylines: Craftartists - Narratives of Identity. Cambridge, Massachusetts and London: Harvard University Press, 1999.

MONDADA, L; DUBOIS, D. (2014). Construção de objetos de discurso e categorização: uma abordagem dos processos de referenciação: In: CAVALCANTE, M. M. et al. (Org.). Referenciação. São Paulo: Contexto, 2014, p. 17-52.

MONDADA, L. A entrevista como acontecimento interacional: abordagem linguística e interacional. RUA, [S.1.], 1997, v. 3, n. 1, p. 59-86.

OJIMA, R.; FUSCO, W. Migrações nordestinas no Século 21: um panorama recente. São Paulo: Edgard Blücher, 2014.

OLIVEIRA, L. M.; BASTOS, L.C. Aspectos da dinâmica da narração de histórias por pessoas com afasia. Calidoscópio. São Leopoldo, 2012, v.10, n.2, p.194-210.

PENNA, M. Relatos de migrantes: questionando as noções de perda de identidade e desenraizamento. In: SIGNORINI, I. (Org.). Lingua(gem) e identidade. Campinas: Mercado das Letras, 1998, p. 89-111. PERAZZO, P. F. Narrativas orais de histórias de vida. Comunicação \& Inovação, São Caetano do Sul, SP, 2015, v. 16, n. 30, p. 121-131, jan./abr.

SILVA, T. T. A produção social da identidade e da diferença. In: SILVA, T. T. (Org.). Identidade e diferença. Petrópolis: Vozes, 2000, p. 73-102.

\section{Notas}

* Doutora em Linguística Aplicada pela Universidade do Vale do Rio dos Sinos (UNISINOS). Professora da Universidade Estadual do Maranhão (UEMA).

** Doutor em Linguística pela UNICAMP. Docente do Programa de Pós-Graduação em Linguística Aplicada da Universidade do Vale do Rio dos Sinos (UNISINOS). 